\title{
Investigation of Wind Energy Potential at Selected Locations in the Volta Region of Ghana
}

\author{
Gabriel Nii Laryea ${ }^{1}$, Kwabena A. Otu-Danquah ${ }^{2}$ \\ ${ }^{1}$ CSIR-Institute of Industrial Research, Accra, Ghana.Email: gabniilaryea@yahoo.com \\ ${ }^{2}$ Energy Commission, Renewable Energy Division, Accra, Ghana
}

\begin{abstract}
The cost of extending electrical power systems to remote areas is expensive and the option is to decentralise small scale energy power systems that could meet the demand in those areas. Wind potential at selected locations in Ghana has been studied for wind energy purpose since there is an increase in socio-economic development in the country. Four (4) of the three-cup anemometers and data-loggers were installed on a 20-m and 30m masts at Amedzofe, Anloga, Areeba-Nkwanta and Kue-Nkwanta (all in the Volta region). The recorded data were analyzed using STATISTICAL software and calculations were made to obtain the Weibull distribution two-parameters and prediction for hourly, monthly mean wind speeds and mean wind power densities were predicted at $50 \mathrm{~m}$ above ground level. Among the selected sites, the mean wind power density of Amedzofe and Anloga fell into Classes 3 and 6 of the commercially international system of wind classification respectively, while Areeba-Nkwanta and Kue-Nkwanta fell into Class 2. Anloga is therefore a suitable site for wind power generation to serve the community.
\end{abstract}

Keywords: Wind power potential; Wind atlas analysis and application program (WAsP); Weibull distribution; Wind speed; Wind power density.

\section{Introduction}

The rapid development in wind energy technology has made it convenient to apply the conventional energy systems. Wind as an inexhaustible resource is noted to provide significant quantities of energy to support livelihood in developing countries. However, because Ghana has an abundance of firewood but greater part of its energy comes from fossil fuel. It has been observed that the use of fossil fuel is rather getting more expensive and also causing deforestation which affects the environment.

The cost of extending electrical power systems to remote areas is expensive and a way out is to decentralize small scale energy power systems that could meet the demand in those areas. Even a little affordable electricity cost could contribute immensely to the quality of life in developing countries (Celik, 2003a and b).

Measurement of wind speed in some parts of Ghana showed a reasonable potential for power systems application, but this source has not been harnessed for many years. This may be due to lack of commitment on the part of government to make the huge investment to harness solar energy.

It has been established that the location for wind energy conversion systems installation must be selected based on factors such as high mean wind speed, acceptable daily, seasonal variations and both limited turbulence levels and extreme winds (Bansal et al., 2002). Benefits obtained from energy system for small rural communities fall into three categories namely energy to improve livelihood; to improve agricultural productivity and for small scale industries (Nayar et al., 1991). In 2005, the energy sector targeted to establish at least $50 \mathrm{MW}$ wind farm along the coastal plains, and also to introduce 50 small wind turbines of $1 \mathrm{~kW}$ capacity in off-grid locations with good moderate wind speeds. It has been estimated that the demand of electricity from national grid would grow from $6,900 \mathrm{GWh}$ in 2000 to about $18,000 \mathrm{GWh}$ by 2015 (i.e $740 \mathrm{GWh} /$ year) and would reach 24, 000 GWh by 2020 (i.e $1200 \mathrm{GWh}$ /year) (Ghana Energy Commission, 2006).

The objective of this paper is to measure and predict the wind energy potential at some selected locations in Ghana. 


\section{Theory and analysis of wind speed and wind} power density

\subsection{Mathematical analysis on wind speed}

In order to predict wind speed at any height above ground level, a measured data at a known height is needed as input to a software - Wind Atlas Analysis and Application Program (WAsP), Denmark that uses a formula expressed as

$$
v=v_{O} 2.5^{\left(0.37-0.0881 \ln \left(\frac{v_{o}}{1-0.0881 \ln \left(v_{o}\right)}\right)\right)}
$$

Feregh (1993) revealed a formula to predict wind speed through horizontal velocity variation with height that could be predicted using the expression.

$$
v=v_{o}\left(\frac{H}{H_{0}}\right)^{\alpha}
$$

where $v_{o}$ is the wind speed at height above the ground level $H_{o}, v$ is the wind speed at height $H(\mathrm{~m})$ above ground level and $\alpha$ is the roughness factor that is an experimental exponent correction which depends on the site type. The value of $\alpha$ varies from 0.1 to 0.4 (Tchinda and Kaptouom, 2004).

The Weibull, Rayleigh and Lognormal distribution functions are the most commonly used in wind power research analyses. However, the Weibull distribution model has been shown to be the best fitting among the models (Celik, 2003b). The two parameters function used in the Weibull distribution function are given as

$$
f_{w}(v)=\left(\frac{k}{c}\right)\left(\frac{v}{c}\right)^{k-1} \exp \left[-\left(\frac{v}{c}\right)^{k}\right]
$$

where $f_{w}(v)$ is the Weibull probability of observing wind speed $v(\mathrm{~m} / \mathrm{s}), k$ is the dimensionless Weibull shape parameter and $\mathrm{c}$ is the Weibull scale parameter in $\mathrm{m} / \mathrm{s}$.

The value of $k$ ranges from 1.5 to 3.0 for most wind conditions and the for Rayleigh distribution the shape parameter is 2.0 . The parameters can also be calculated as

$$
\left.\begin{array}{c}
\frac{v}{\mathrm{r}\left(1+\frac{1}{\mathrm{k}}\right)} \\
\mathrm{k}=\left(\frac{\sigma}{\mathrm{k}}\right)^{-1.086}
\end{array}\right\}
$$

where $\quad 1 \leq k \geq 10$. The scale parameter $\mathrm{c}$ - indicates how "windy" a wind site under consideration is and the shape parameter $k$ - how peaked the wind distribution is.

\subsection{Mathematical analysis on turbulence intensity}

The wind turbulence intensity has been given as

$$
\text { Turbulence Intensity }=\frac{\text { standards deviation }}{\text { average wind speed }} \text { (6) }
$$

\subsection{Mathematical analysis on wind power density}

The power of the wind that flows at speed $\mathrm{v}$ through a blade sweep area $\mathrm{A}$ increases as the cube of its speed and is given by (Akpinar and Akpinar, 2004) as

$$
P(v)=\frac{1}{2} \rho A v^{3}
$$

Where $\rho$ is the air density, A is the rotor swept area exposed to the wind $\left(\mathrm{m}^{2}\right)$, The wind power density is given as

$$
\frac{P_{v}}{A}=\frac{1}{2} \rho v^{3}
$$

It can also be expressed in terms of the Weibull parameters as

$$
\frac{P_{v}}{A}=\frac{1}{2} \rho c^{3}\left(1+\frac{3}{k}\right)
$$

\section{Wind data collection and evaluation}

\subsection{Wind speed}

A good wind source is critical to the success of a commercial wind energy project (Kose, 2004) recommended to have wind speed data for five years, if data are available. The availability of energy from the wind increases in proportion to the cube of the wind speed, which also increases with height above the ground. The minimal annual average wind speed for a wind project should exceed $4 \mathrm{~m} / \mathrm{s}$ at a height of $10 \mathrm{~m}$ above the ground. The wind data used in this research were measured and recorded every 10 minutes at Amedzofe, Anloga, Areeba-Nkwanta and Kue-Nkwanta. Generator cup anemometers were installed at $20 \mathrm{~m}$ (at Amedzope and Anloga) and $30 \mathrm{~m}$ (at Areeba and Kue Nkwanta) above ground level.

A data logger (NRG Data Processing Software) was used to capture and record the wind data. The lose of data collected for the periods was $1.4 \%$ during this 
research. The NRG reads data files from Symphonic, Wind Explorer and converts raw data to Tab Delimited ASCII format output. The software generates monthly or comprehensive site reports and also a time series wind data recorder, collecting wind speed average and standard deviation, average wind direction and one additional sensor average for each 10 minutes interval. The data was later downloaded on a Personal Computer for further off-line data processing analyses.

Studies on wind power potential have been performed using Sonic Detection and Ranging SODAR (PAO) to measure and record average wind speed from 20 to $200 \mathrm{~m}$. (Chaudhry et al., 2007and 2009) stated that sometimes simple average wind speeds may not reflect the actual wind power potential of an area.

\subsection{Wind power density}

The average values of wind speed of an area do not truly represent its potential, because the information regarding frequency distribution of wind speed is suppressed in the process of averaging wind speed. Wind power density is determined by the amount of electricity that wind turbines produce and it depends upon the amount of energy in the wind passing through the area swept by the wind turbine blades in a unit time (Kose, 2004).

It is well known that if the speed doubles, power increases by a factor of eight, but in practice, the relationship between the power output of a wind turbine and wind speed does not follow a cubic relationship. This is because Wind density also depends on air density, the higher the height, the lower the air density (Chaudhry et al., 2007a).

\subsection{Results and discussion}

The wind speeds at Amedzofe, Anloga, AreebaNkwanta and Kue-Nkwanta were measured for a period of a year (i.e. November 2006 - October 2007). The recorded data were off-loaded and analyzed using STATISTICAL software. Calculations were made to obtain the Weibull distribution parameters (scale c and shape $\mathrm{k}$ ), and prediction at $50 \mathrm{~m}$ above ground level for hourly, monthly mean wind speeds and mean wind power densities were investigated.

\subsection{Mean windspeed}

The values of both recorded and predicted mean wind speed $\mathrm{v}_{\mathrm{m}}$, for the period November 2006 to October 2007 and present in Table 1 for $20 \mathrm{~m}, 30 \mathrm{~m}$ and $50 \mathrm{~m}$. From Table 1, it was observed that, monthly maximum mean wind speed for Amedzofe, Anloga, Kue and Nkwanta were $6.6 \mathrm{~m} / \mathrm{s}$ (March), $8.1 \mathrm{~m} / \mathrm{s}$ (February and July), $4.9 \mathrm{~m} / \mathrm{s}$ (April) and $5.7 \mathrm{~m} / \mathrm{s}$ (January) respectively, while minimum mean winds speeds were $4.2 \mathrm{~m} / \mathrm{s}$ (December), $5.5 \mathrm{~m} / \mathrm{s}$ (November and January), $3.4 \mathrm{~m} / \mathrm{s}$ (August) and $2.7 \mathrm{~m} / \mathrm{s}$ (August) respectively. The yearly mean wind speed values for Amedzofe, Anloga, Areeba-Nkwanta and KueNkwanta were 5.2, 7.0, 4.1 and $3.8 \mathrm{~m} / \mathrm{s}$ respectively. The analyzed data show that the wind speed differs from month to month in all the selected locations.

The monthly mean wind speeds distribution for the various locations are represented in Fig. 1. Mean wind speed at Anloga showed the highest values in all the months, this may be due to the low turbulence intensity. The diurnal wind speed for the locations for January, February, March and April are presented from Fig. 2 to Fig. 5 respectively. The diurnal wind speed pattern depends on the location and the month. In the case of Anloga, the diurnal wind speed has its minimum during the mid-night hours and maximum during the afternoon (i.e between 16.00-18.00 GMT).

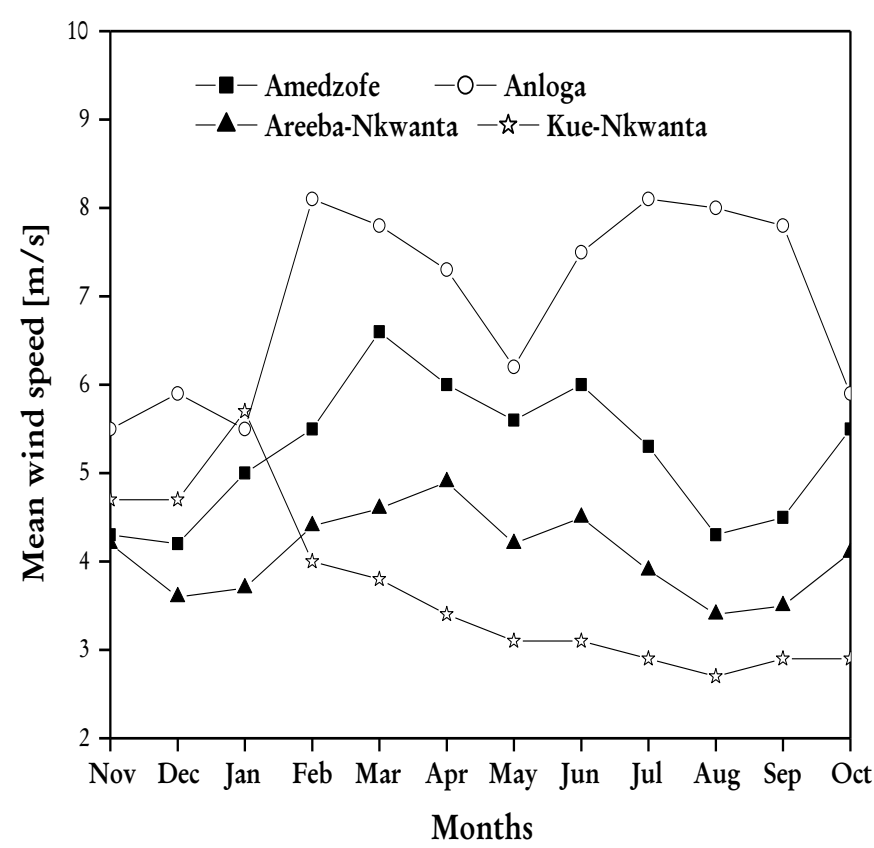

Fig. 1: Monthly mean wind speed for the various locations. 


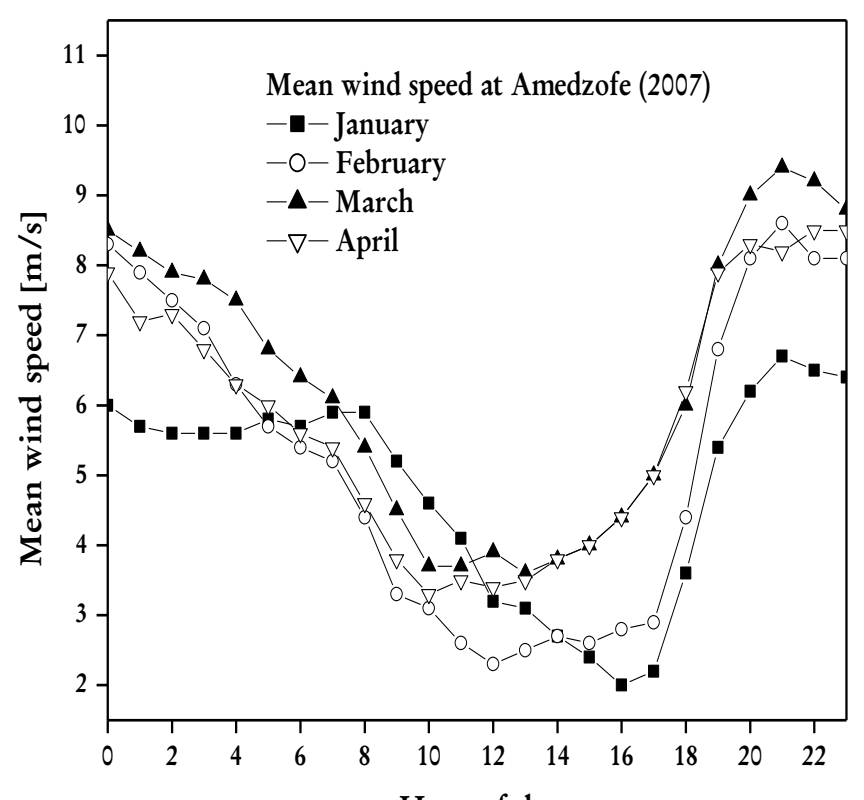

Hour of day

Fig. 2: Diurnal variations of wind speed in Amedzofe for these months.

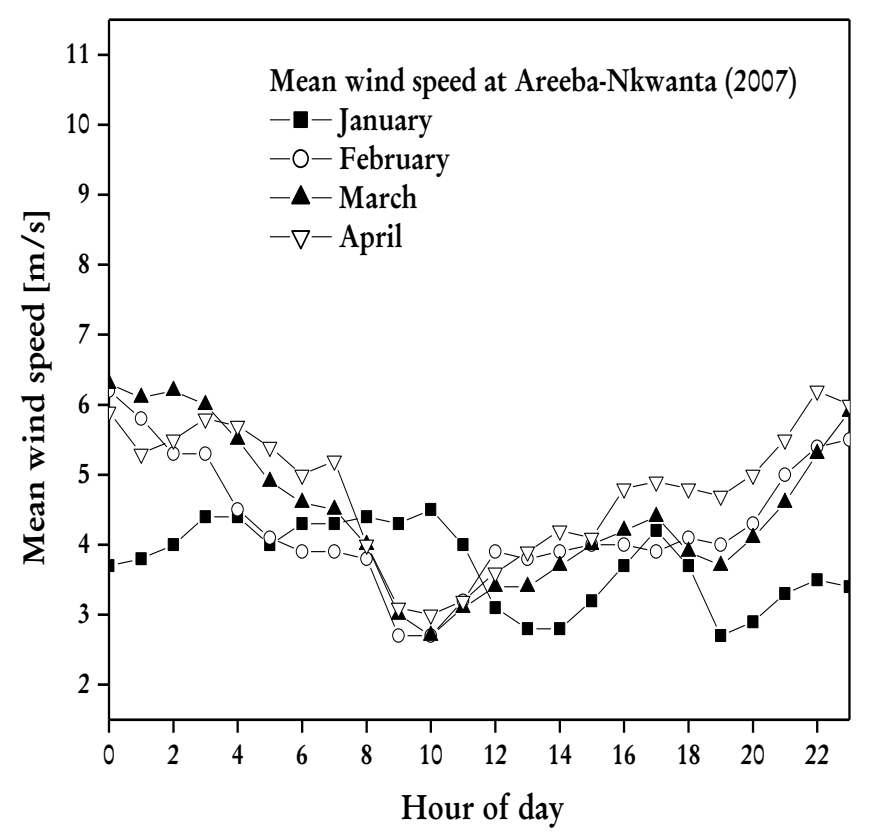

Fig. 4: Diurnal variations of wind speed in Areeba-Nkwanta for these months.

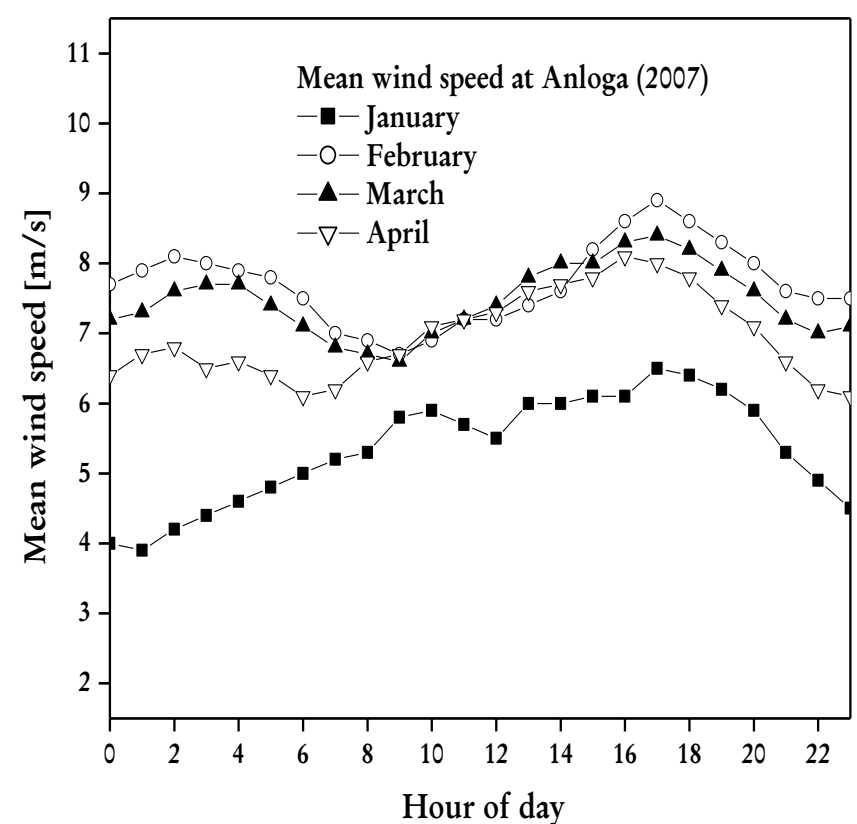

Fig. 3: Diurnal variations of wind speed in Anloga for these months.

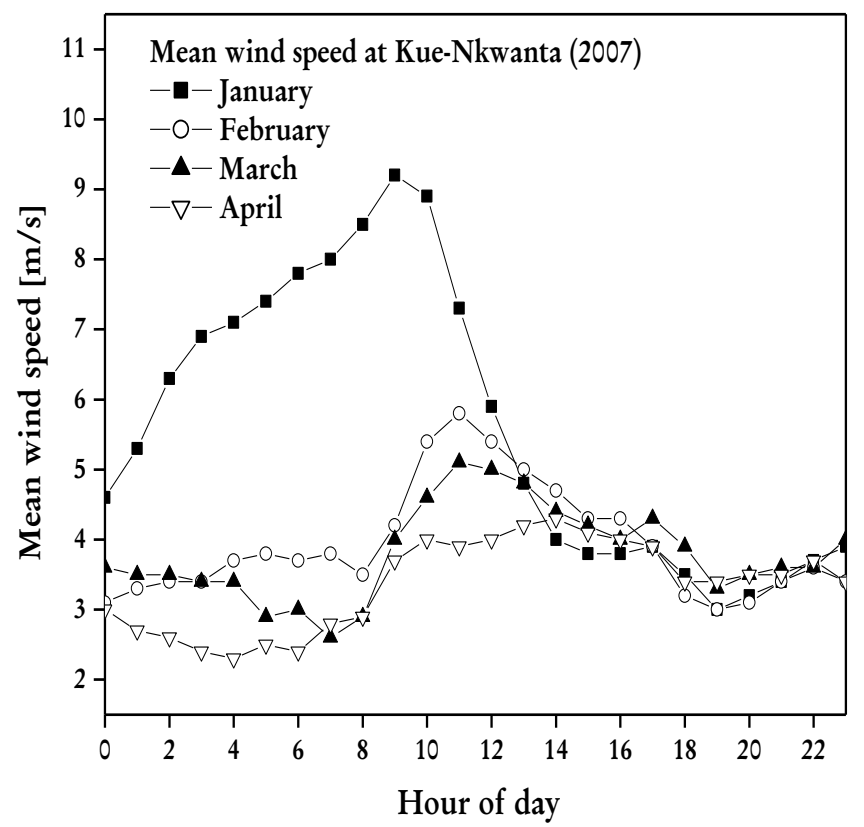

Fig. 5: Diurnal variations of wind speed in Kue-Nkwanta for these months.

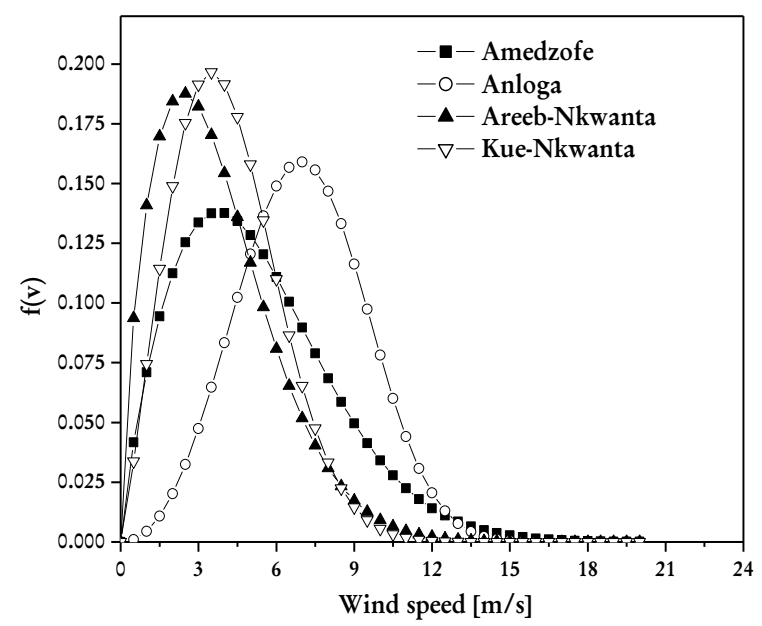

Fig. 6: Yearly Weibull probability density function distributions for the sites. 
Table 1

The monthly mean wind speed $\mathrm{v}_{\mathrm{m}}$ measured, predicted values and their standard deviations $(\sigma)$ between November 2006 and October 2007.

\begin{tabular}{|c|c|c|c|c|c|c|c|c|c|c|c|c|c|}
\hline \multirow{3}{*}{ Month } & \multirow{3}{*}{$\begin{array}{l}\text { Para- } \\
\text { meters }\end{array}$} & \multirow{2}{*}{\multicolumn{3}{|c|}{ Amedzofe }} & \multicolumn{6}{|c|}{ Locations in Ghana } & \multirow{2}{*}{\multicolumn{3}{|c|}{ Kue-Nkwanta }} \\
\hline & & & & & \multicolumn{4}{|c|}{ Anloga Areeba- } & \multicolumn{2}{|c|}{ Nkwanta } & & & \\
\hline & & $20 \mathrm{~m}$ & $50 \mathrm{~m} *$ & $50 \mathrm{~m} * *$ & $20 \mathrm{~m}$ & $50 \mathrm{~m} *$ & $50 \mathrm{~m} * *$ & $30 \mathrm{~m}$ & $50 \mathrm{~m} *$ & $50 \mathrm{~m} * *$ & $30 \mathrm{~m}$ & $50 \mathrm{~m} *$ & $50 * \%$ \\
\hline \multirow[t]{2}{*}{ Nov. } & $v_{m}$ & 3.2 & 4.2 & 4.3 & 4.2 & 5.4 & 5.5 & 3.6 & 4.1 & 4.2 & 4.0 & 4.6 & 4.7 \\
\hline & $\sigma$ & 1.8 & 2.2 & 2.3 & 1.6 & 1.9 & 2.1 & 1.4 & 1.6 & 1.7 & 2.2 & 2.5 & 3.0 \\
\hline \multirow[t]{2}{*}{ Dec. } & $v_{m}$ & 3.2 & 4.1 & 4.2 & 4.5 & 5.8 & 5.9 & 3.1 & 3.6 & 3.6 & 4.0 & 4.6 & 4.7 \\
\hline & $\sigma$ & 1.8 & 2.2 & 2.4 & 1.5 & 1.8 & 2.0 & 1.4 & 1.6 & 1.7 & 2.8 & 3.1 & 3.3 \\
\hline \multirow[t]{2}{*}{ Jan. } & $v_{m}$ & 3.8 & 4.8 & 5.0 & 4.2 & 5.3 & 5.5 & 3.2 & 3.6 & 3.7 & 4.9 & 5.6 & 5.7 \\
\hline & $\sigma$ & 2.2 & 2.6 & 2.8 & 1.5 & 1.8 & 1.9 & 1.5 & 1.7 & 1.8 & 3.0 & 3.6 & 3.6 \\
\hline \multirow[t]{2}{*}{ Feb. } & $v_{m}$ & 4.1 & 5.3 & 5.5 & 6.2 & 7.7 & 8.1 & 3.7 & 4.3 & 4.4 & 3.4 & 3.9 & 4.0 \\
\hline & $\sigma$ & 2.6 & 3.2 & 3.4 & 1.6 & 1.9 & 2.2 & 2.0 & 2.0 & 2.3 & 2.3 & 2.5 & 2.7 \\
\hline \multirow[t]{2}{*}{ Mar. } & $v_{m}$ & 5.0 & 6.3 & 6.6 & 5.9 & 7.5 & 7.8 & 3.9 & 4.5 & 4.6 & 3.3 & 3.8 & 3.8 \\
\hline & $\sigma$ & 2.8 & 3.3 & 3.5 & 1.7 & 2.0 & 2.3 & 2.0 & 2.2 & 2.3 & 2.0 & 2.2 & 2.3 \\
\hline \multirow[t]{2}{*}{ Apr. } & $v_{m}$ & 4.6 & 5.8 & 6.0 & 5.5 & 7.0 & 7.3 & 4.2 & 4.8 & 4.9 & 2.9 & 3.4 & 3.4 \\
\hline & $\sigma$ & 2.5 & 3.0 & 3.4 & 2.1 & 2.5 & 2.8 & 2.0 & 2.2 & 2.3 & 1.8 & 2.0 & 2.1 \\
\hline \multirow[t]{2}{*}{ May } & $v_{m}$ & 4.2 & 5.4 & 5.6 & 4.7 & 6.0 & 6.2 & 3.6 & 4.1 & 4.2 & 2.7 & 3.1 & 3.1 \\
\hline & $\sigma$ & 2.6 & 3.2 & 3.5 & 2.1 & 2.5 & 2.8 & 1.7 & 1.9 & 2.0 & 2.1 & 2.4 & 2.5 \\
\hline \multirow[t]{2}{*}{ Jun. } & $v_{m}$ & 4.6 & 5.8 & 6.0 & 5.7 & 7.2 & 7.5 & 3.9 & 4.5 & 4.5 & 2.6 & 3.1 & 3.1 \\
\hline & $\sigma$ & 2.5 & 3.0 & 3.3 & 2.4 & 2.9 & 3.2 & 1.7 & 1.9 & 2.0 & 1.7 & 1.9 & 2.0 \\
\hline \multirow[t]{2}{*}{ Jul. } & $v_{m}$ & 4.1 & 5.2 & 5.3 & 6.1 & 7.7 & 8.1 & 3.3 & 3.8 & 3.8 & 2.5 & 2.9 & 2.9 \\
\hline & $\sigma$ & 2.1 & 2.6 & 2.8 & 1.6 & 1.8 & 2.1 & 1.6 & 1.8 & 2.2 & 1.1 & 1.2 & 1.3 \\
\hline \multirow[t]{2}{*}{ Aug. } & $v_{m}$ & 3.3 & 4.3 & 4.3 & 6.1 & 7.6 & 8.0 & 2.9 & 3.3 & 3.4 & 2.3 & 2.7 & 2.7 \\
\hline & $\sigma$ & 1.9 & 2.4 & 2.6 & 1.7 & 2.0 & 2.2 & 1.6 & 1.8 & 1.9 & 1.1 & 1.2 & 1.3 \\
\hline \multirow[t]{2}{*}{ Sep. } & $v_{m}$ & 3.4 & 4.4 & 4.5 & 6.0 & 7.5 & 7.8 & 3.0 & 3.5 & 3.5 & 2.5 & 2.9 & 2.9 \\
\hline & $\sigma$ & 2.2 & 2.7 & 2.9 & 1.7 & 2.0 & 2.2 & 1.6 & 1.8 & 1.9 & 1.5 & 1.7 & 1.8 \\
\hline \multirow[t]{2}{*}{ Oct. } & $v_{m}$ & 4.2 & 5.4 & 5.5 & 4.5 & 5.7 & 5.9 & 3.4 & 3.9 & 4.1 & 2.3 & 2.7 & 2.9 \\
\hline & $\sigma$ & 2.2 & 2.6 & 2.8 & 2.0 & 2.4 & 2.6 & 1.7 & 1.9 & 1.9 & 1.5 & 1.6 & 1.7 \\
\hline \multirow[t]{2}{*}{ Yearly } & $v_{m}$ & 4.0 & 5.1 & 5.2 & 5.3 & 6.7 & 7.0 & 3.5 & 4.0 & 4.1 & 3.1 & 3.6 & 3.8 \\
\hline & $\sigma$ & 2.3 & 2.8 & 3.0 & 1.8 & 2.1 & 2.4 & 1.7 & 1.9 & 2.0 & 1.9 & 2.2 & 2.3 \\
\hline \multicolumn{2}{|c|}{$\begin{array}{l}\text { Turbulence } \\
\text { Intensity }\end{array}$} & 0.6 & 0.6 & 0.6 & 0.3 & 0.3 & 0.3 & 0.5 & 0.5 & 0.5 & 0.6 & 0.6 & 0.6 \\
\hline
\end{tabular}

N.B $>*$ - using eq. (1)** - using eq. (2)

\subsection{Weibull distribution}

The yearly values of the two Weibull parameters, the scale $\mathrm{c}(\mathrm{m} / \mathrm{s})$ and shape $\mathrm{k}$ (dimensionless) were calculated from November 2006 to October 2007 and presented in Table 2 for the various locations. The $\mathrm{k}-$ values are smaller than the $\mathrm{c}-$ values. The yearly values of the shape parameter $\mathrm{k}$ range between 1.82 and 3.20 which validates with the range given by other scientists such as Celik (2003b). This indicates that the failure rate increases with time. The scale parameter $\mathrm{c}$ ranges between 4.63 and $7.82 \mathrm{~m} / \mathrm{s}$. The Weibull probability distribution of wind speeds are shown in Fig, 6. The highest peak was observed at KueNkwanta while the lowest was at Amedzofe, but Anloga showed a normal distribution among all the locations.

Table 2

Monthly shape parameters, $\mathrm{k}$, and scale parameters, c, in selected locations in Ghana

\begin{tabular}{cccccc}
\hline Monthly & Parameters & Amedzofe & Anloga & Areeba-Nkwanta & Kue-Nkwanta \\
\hline \multirow{2}{*}{ November } & $\mathrm{k}$ & 1.97 & 2.85 & 2.67 & 1.63 \\
& $\mathrm{c}$ & 4.85 & 6.17 & 4.72 & 5.25 \\
December & $\mathrm{k}$ & 1.83 & 3.24 & 2.67 & 1.47 \\
& $\mathrm{c}$ & 4.72 & 6.58 & 4.06 & 3.98 \\
\hline
\end{tabular}




\begin{tabular}{lccccc}
\hline \multirow{2}{*}{ Monthly } & Parameters & Amedzofe & Anloga & Areeba-Nkwanta & Kue-Nkwanta \\
\hline January & $\mathrm{k}$ & 1.88 & 3.17 & 2.19 & 1.65 \\
February & $\mathrm{c}$ & 5.63 & 6.14 & 4.18 & 4.14 \\
& $\mathrm{k}$ & 1.69 & 4.12 & 2.02 & 1.53 \\
March & $\mathrm{c}$ & 6.16 & 8.92 & 4.97 & 4.89 \\
& $\mathrm{k}$ & 1.99 & 3.77 & 2.12 & 1.73 \\
April & $\mathrm{c}$ & 7.45 & 8.63 & 5.19 & 5.16 \\
& $\mathrm{k}$ & 1.85 & 2.83 & 2.27 & 1.69 \\
May & $\mathrm{c}$ & 6.76 & 8.19 & 5.53 & 5.49 \\
& $\mathrm{k}$ & 1.67 & 2.37 & 2.24 & 1.26 \\
June & $\mathrm{c}$ & 6.27 & 7.00 & 4.74 & 4.52 \\
& $\mathrm{k}$ & 1.91 & 2.52 & 1.86 & 1.61 \\
July & $\mathrm{c}$ & 6.76 & 8.45 & 4.39 & 5.02 \\
& $\mathrm{k}$ & 2.00 & 4.33 & 1.88 & 2.39 \\
August & $\mathrm{c}$ & 5.98 & 8.90 & 3.83 & 4.40 \\
& $\mathrm{k}$ & 1.73 & 4.06 & 1.94 & 2.21 \\
September & $\mathrm{c}$ & 4.82 & 8.82 & 3.95 & 3.84 \\
\multirow{2}{*}{ Yearly } & $\mathrm{k}$ & 1.61 & 3.95 & 2.31 & 1.68 \\
& $\mathrm{c}$ & 5.02 & 8.61 & 4.63 & 3.92 \\
& $\mathrm{k}$ & 1.82 & 3.20 & 2.18 & 1.68 \\
\hline
\end{tabular}

\subsection{Wind power density}

The mean wind power densities for Amedzofe, Anloga, Areeba-Nkwanta and Kue-Nkwanta have been calculated. The monthly variation of the mean wind power densities have been presented in Fig. 7. It was observed that the maximum mean wind power densities were obtained during the months March, February/ and July, April and January at Amedzofe, Anloga, Areeba-Nkwanta and Kue-Nkwanta respectively. The predicted maximum mean wind power densities values were 328, 606, 134 and 211 $\mathrm{W} / \mathrm{m}^{2}$ for Amedzofe, Anloga, Areeba-Nkwanta and Kue-Nkwanta accordingly. From the values obtained Amedzofe and Anloga were in Classes 3 and 6 (i.e. Moderate/Fair and Outstanding) respectively according to the International Standard on wind power classifications at $50 \mathrm{~m}$ height, while AreebaNkwanta and Kue-Nkwanta are in the Marginal class. Figure 8 shows the monthly variations of the mean wind speed and wind power density for Anloga. The wind power density increased exponentially with an increase in wind speed. The air densities at the measured heights were not measured in this research, but an average standard value of $1.2 \mathrm{~kg} / \mathrm{m}^{3}$ was used for the calculation based on standard sea level condition (i.e. $\mathrm{P}=101325 \mathrm{bar}$ and $1=20^{\circ} \mathrm{C}$ ). The annual energy power to be predicted for each location was not presented in this paper.

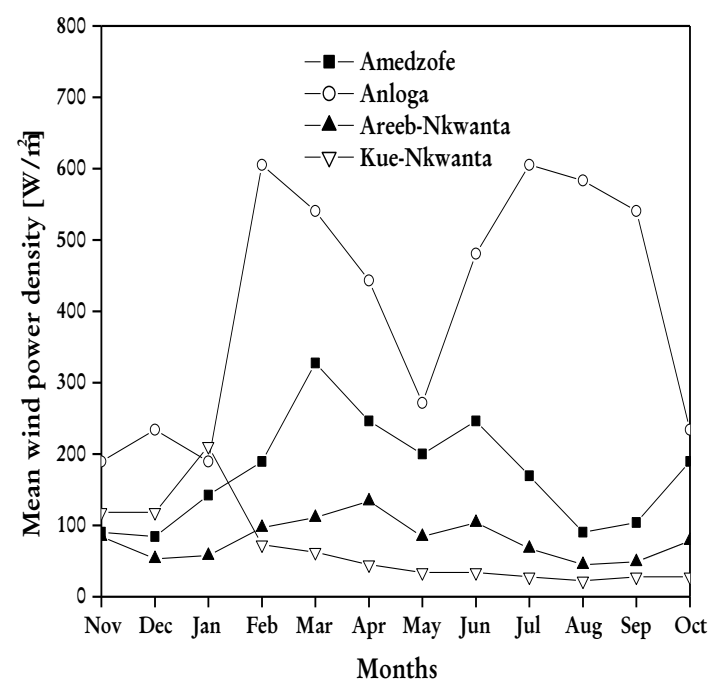

Fig. 7: Variations of months and mean wind power density for a year at the locations.

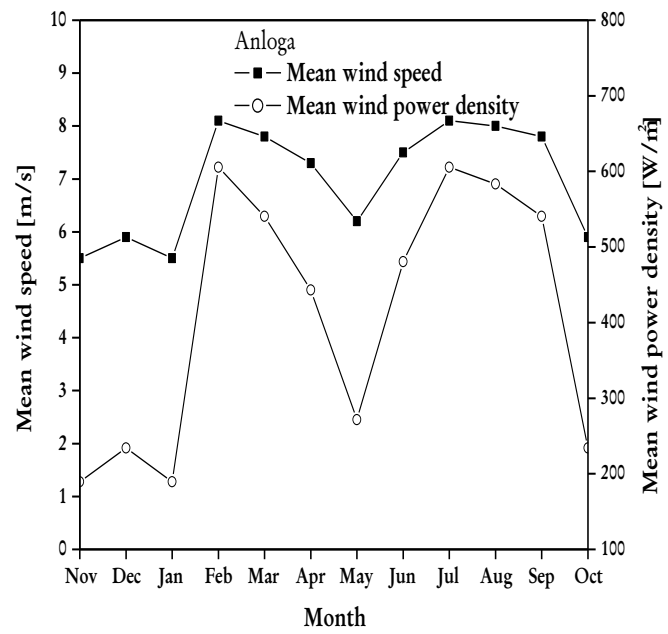

Fig. 8: Monthly variations of the mean wind speed and wind power density for Anloga. 


\section{Conclusions}

In this study, a year (November 2006 - October 2007) wind speed data of Amedzofe, Anloga, AreebaNkwanta and Kue-Nkwanta have been statistically analysed. The probability density distributions for the various locations have been derived from the data. The distributional two parameters were calculated, identified and fitted on monthly basis for the distribution measurement. The maximum mean wind speed for Amedzofe, Anloga, Areeba-Nkwanta and Kue-Nkwanta are 6.6, 8.1, 4.9 and $5.7 \mathrm{~m} / \mathrm{s}$ respectively and the corresponding wind power density are $328,606,134$ and $211 \mathrm{~W} / \mathrm{m}^{2}$ respectively. The wind energy potential of the locations has been case studied based on the wind speed on the Weibull model. It can be concluded that Amedzofe and Anloga are considered as areas of wind power potentials with moderate/fair and excellent resource potentials.

\section{Acknowledgements}

The authors wish to express their gratitude to $\mathrm{Mr}$. Frederick Ken Appiah of the Energy Commission, Ghana for his assistance. They are also grateful to Mr. Enoch Quaye a Graduate student of the University of Ghana, Legon for analyzing the statistical data in this paper.

\section{References}

Akpinar, E.K., and Akpinar, S., (2004). Determination of Wind Energy Potential for Maden-Elazig, Turkey. Energy Conversion and management, Vol. 45, pp. 9012914.

Bansal, C., Bhatti, T.S., and Kothari, D.P., (2002). On Some of the Design Aspects of Wind Energy Conversion Systems. Energy Conversion and Management, Vol. 43, pp. 2175-2187.
Celik, A.N., (2003). Assessing the Suitability Of Wind Speed Probability Distribution Functions Based On Wind Power Density, Renewable Energy, Vol. 28, pp. 1563-1574.

Celik, A.N., (2003). Weibull Representative Compressed Wind Speed Data for Energy and Performance Calculations of Wind Energy Systems. Energy Conversion and Management, Vol. 44, pp. 3057-3072.

Chaudhry, Q.Z., Khan, A.H., and Ahmad, J., (2007). A Study of Wind Power Potential at Sabzal KotRajanpur (Punjab) Using SODAR. Technical Report No. SODAR -01/2007, pp. 1-11.

Chaudhry, Q.Z., Khan, A.H., and Ahmad, J., (2009). A Study of Wind Power Potential at Kallar Kahar Chakwal (Punjab) Using SODAR. Technical Report No. SODAR -01/2009, pp. 1-11.

Feregh, G.M., (1993). Wind energy potential in Bahrain. Energy Conversion and Management, Vol. 34,No.6, pp. 499-506.

Ghana Energy Commission, (2006). Strategic National Energy Plan 2006-2020 and Ghana Energy Policy, Main Version.

Kose, R., (2004). An Evaluation of Wind Energy Potential As A Power Generation Source In Kutahya, Turkey. Energy Conversion and Management, Vol. 45, pp.16311641.

Nayar, C.V., Thomas, F.P., Phillips, S.J., and James, W.L., (1991). Design Considerations for Appropriate Wind Energy Systems in Developing Countries. Renerwable Energy, Vol. 1, No.(5/6): pp.713-722.

Tchinda, R. and Kaptouom, E., (2003). Wind Energy in Adamaoua And North Cameroon Provinces, Energy Conversion and Management, 44: pp. 845-857. 